\title{
Familial adult onset of Krabbe's disease resembling hereditary spastic paraplegia with normal neuroimaging
}

\author{
N P S Bajai, A Waldman, R Orrell, N W Wood, K P Bhatia
}

J Neurol Neurosurg Psychiatry 2002;72:635-638

Krabbe's disease (globoid cell leucodystrophy) is a disorder involving the white matter of the peripheral and central nervous systems. Mutations in the gene for the lysosomal enzyme galactocerebrosidase (GALC) result in low enzymatic activity and decreased ability to degrade galactolipids found in myelin. The disease is classically of infantile onset, but adult onset cases have been reported. Magnetic resonance imaging (MRI) of the brain shows characteristic abnormalities. A unique family with Krabbe's disease is described, with proven GALC deficiency but normal MRI. A neurological phenotype is present in heterozygotes and the family shows the extent of homozygotic phenotypic diversity that can be seen in this disorder.

$\mathrm{K}$ rabbe's disease, or globoid leucodystrophy, is an autosomal recessive disorder caused by a deficiency in the activity of the enzyme galactocerebrosidase (GALC). ${ }^{1}$ The condition has been mapped to chromosome 14q24.3q32.1 and the GALC gene has recently been cloned. ${ }^{23}$ Deficiency of GALC impairs cleavage of the galactose moiety from galactosylceramide. This leads to accumulation of galactosylceramide within multinucleated macrophages of the white matter, forming globoid cells. A metabolite of galactosylceramide, psychosine, also accumulates and is toxic to oligodendroglia. This ultimately results in damage to the white matter of both peripheral and central nervous systems. ${ }^{4}$ The disease is confirmed by markedly reduced GALC activity in peripheral blood leucocytes. ${ }^{4}$

The disease may be subdivided into three types: the more common infantile form with onset within the first six months ${ }^{4}$; a juvenile form presenting between two and 10 years; and a rarer adult form with onset after 10 years. ${ }^{5-9}$ The infantile form is the most severe, with central demyelination causing irritability, spasticity, ataxia, and seizures. Blindness from optic atrophy, cortical blindness, and deafness may all occur. Peripheral demyelination presents with limb weakness and areflexia. Progressive psychomotor decline results in quadriparesis and death within a few years of onset. Nerve conduction studies show a demyelinating peripheral neuropathy, and magnetic resonance imaging (MRI) shows central demyelination, most prevalent in the periventricular area and centrum semiovale with sparing of the subcortical U fibres. The cerebrospinal fluid may show increased protein. ${ }^{4}$

Juvenile and adult forms of the disease have a milder phenotype and a slower rate of progression. Symptoms and signs include spasticity, dementia, ataxia, peripheral neuropathy, and loss of vision. Investigations may show milder abnormalities, and nerve conduction can be normal or only mildly affected. Cerebrospinal fluid can be normal and MRI may be normal early on in the disease. ${ }^{5-9}$

Despite the heterogeneity of the clinical presentation of Krabbe's disease, long standing cases with spasticity alone and normal neuroimaging have not been reported. In this paper, we present the clinical findings of a novel family with adult onset Krabbe's disease with proven enzyme deficiency and normal neuroimaging after 22 years of symptoms in the index case.

\section{CASE 1}

The index case, a 33 year old man, had a history of worsening gait since his teenage years. He was born as a normal vaginal delivery but was two weeks post-term. Initial motor milestones were normal, with normal educational performance subsequently. His motor problems became apparent from the age of 11 with cramping leg pains on vigorous exercise and inability to keep up with the other children in games. He developed a noticeable limp and had difficulty with balance and coordination. He was unable to run after the age of 17 . He lost spontaneous erections by the age of 21 and by the age of 29 was suffering from urinary frequency and urgency. On occasion, he was aware of slurring of his speech.

There was no diurnal variation in his leg weakness. There was no history of visual loss or Lhermitte's or Uthoff's phenomena.

At time of presentation, there was no family history of neurological disease. His mother was fit and well up to the time of separation of his parents. His mother's history after that time is uncertain. There was no history of parental consanguinity.

He was investigated as a child at a tertiary paediatric referral centre and had normal cerebral computed tomography and myelography. At his most recent examination (at the age of 33 ) the findings were as follows. The cranial nerves and fundoscopic appearances were normal. Visual acuity was unimpaired and Ischihara charts showed no deficit in colour vision. The tone and power in his upper limbs were normal and the reflexes were brisk. In the lower limbs, there was a spastic paraparesis with increased tone, sustained ankle clonus, pathologically brisk reflexes, and extensor plantar responses. Abdominal reflexes were intact. There was mild finger-nose ataxia with no dysmetria or dysdiadochokinesis. Sensory examination showed a reduction of light touch and pin prick sensation to the mid-shin. Vibration sense was absent at the toes but joint position sense was normal.

Laboratory investigation results that were normal or within the normal range included the following: plasma electrolytes, liver function, calcium, phosphate, thyroid function, full blood count, vitamin B-12 and folate, syphilis serology, and autoantibody profile. Very long chain fatty acids were normal. Two initial sets of nerve conduction studies six months apart were normal. Somatosensory evoked potentials of the lower limb showed delay in central conduction. Cerebrospinal fluid examination showed normal opening pressure, cell count, and glucose. CSF protein was raised at $0.75 \mathrm{~g} / \mathrm{l}$. Oligoclonal bands were negative.

A galactocerebrosidase assay was carried out according to the methods of Suzuki and Suzuki. ${ }^{1}$ The normal range for 

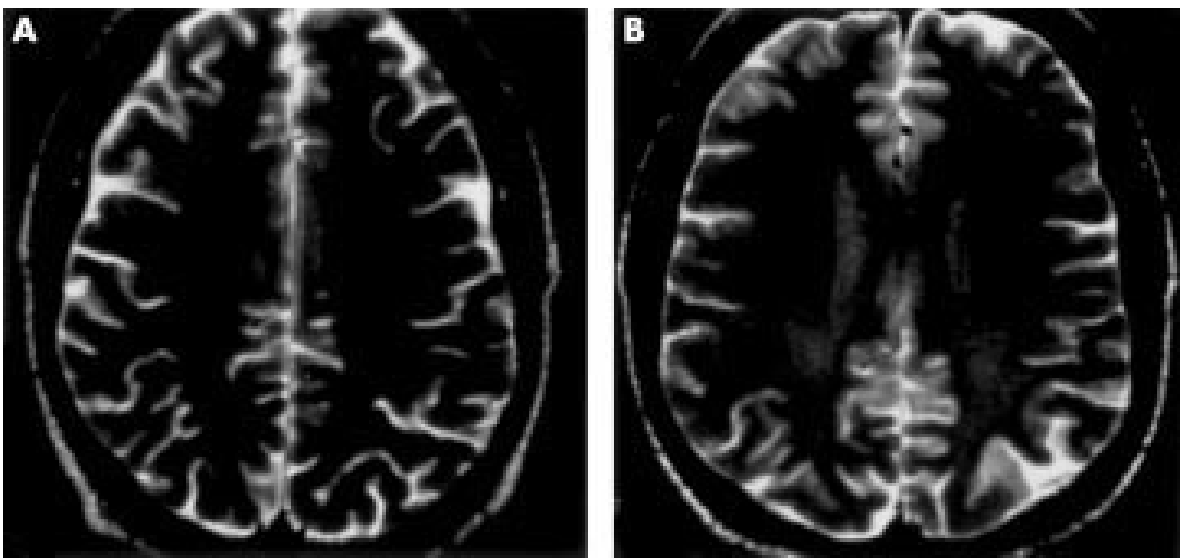

Figure 1 Magnetic resonance imaging in case 1. (A) T2 weighted axial images. Sequence acquisition parameters were identical (standard fast spin echo sequence; $T R=2000 \mathrm{~ms}, \mathrm{TE}=84 \mathrm{~ms}$ ), but with a minor difference in slice angulation. The minor signal variation seen in the posterior white matter of the centrum semiovale is within normal limits. (B) Nine months later, subtle signal abnormality may be present in the parietal and peritrigonal white matter.

galactocerebrosidase in our laboratory is $0.51-3.8 \mathrm{nmol} / \mathrm{h} / \mathrm{mg}$ of protein; samples between 0 and $0.04 \mathrm{nmol} / \mathrm{h} / \mathrm{mg}$ of protein are regarded as being within the homozygous range for Krabbe's disease; samples between 0.12 and $1.8 \mathrm{nmol} / \mathrm{h} / \mathrm{mg}$ of protein are regarded as possibly within the heterozygous range. Galactocerebrosidase levels in the index case revealed an undetectable level of enzyme on two of three tests, and a barely detectable level on the third $(0.08 \mathrm{nmol} / \mathrm{h} / \mathrm{mg}$ of protein). These levels would be compatible with the homozygous range for Krabbe's disease. The remainder of the white cell enzymes were within normal limits. A pseudodeficiency of GALC was thought to be very unlikely on the evidence of reduced GALC levels in other members of the family with neurological signs (discussed below).

DNA analysis showed that the patient was heterozygous for the IVS10DEL30 mutation, which is one of the most common mutations in the gene encoding galactocerebrosidase. A search to identify the second mutation (as he would be a compound heterozygote) was not undertaken. The initial MRI of the brain and the whole spine performed 10 years earlier had been reported as normal (films not available). A repeat MRI of brain and spinal cord from February 2000 was again normal (fig lA). Further MRI brain and spinal cord examinations six and nine months later were reported as "essentially normal," but one of the two radiologists consulted queried a subtle increase in $\mathrm{T} 2$ signal in posterior white matter (fig $1 \mathrm{~B}$ ).

\section{CASE 2}

The 32 year old sibling of the index case presented with a six month history of worsening gait. The left leg was worse affected and had a tendency to drag. There was no history of sphincter disturbance. Vision was normal, as were the upper limbs.

He was born as a normal term vaginal delivery. Developmental milestones and subsequent education were normal. Examination showed normal cranial nerves and upper limbs. He had a spastic paraparesis with pyramidal weakness most pronounced in the left leg. There was reduced temperature sensation to the left knee; the reminder of the sensory examination was normal.

Laboratory results that were normal or within normal range included the following: plasma electrolytes, liver function, calcium, phosphate, thyroid function, full blood count, vitamin B-12 and folate, syphilis serology, autoantibody profile, very long chain fatty acids, nerve conduction studies, electroencephalography, and visual and somatosensory evoked potentials. Neuropsychometry showed no evidence of cognitive decline. CSF examination showed normal opening pressure with normal cell count and glucose. CSF protein was raised at $0.71 \mathrm{~g} / \mathrm{l}$. Oligoclonal bands were negative. Galactocerebrosidase levels were very low and were within the homozygous range for Krabbe's disease $(0.04 \mathrm{nmol} / \mathrm{h} / \mathrm{mg}$ of protein). The remainder of the white cell enzymes were within normal limits. MRI of the brain showed a non-specific lesion in the right anterior thalamus only (fig 2). MRI of the whole spine was normal

\section{CASE 3}

The 57 year old father of cases 1 and 2 had presented to his general practitioner 20 years earlier with a history of tripping over his feet, resulting in several falls. He was referred to his local hospital where examination was apparently normal. The details of any tests done at that time were not available. These problems subsequently resolved.

Current examination was normal apart from brisk lower limb reflexes, which were felt to be pathological. Plantars were flexor. The patient declined neuroimaging and neurophysiological tests, but agreed to a blood sample for GALC levels. The subsequent level of GALC of $1.3 \mathrm{nmol} / \mathrm{h} / \mathrm{mg}$ of protein would be compatible with the heterozygous range for Krabbe's disease in our laboratory, but also overlaps with the lower end

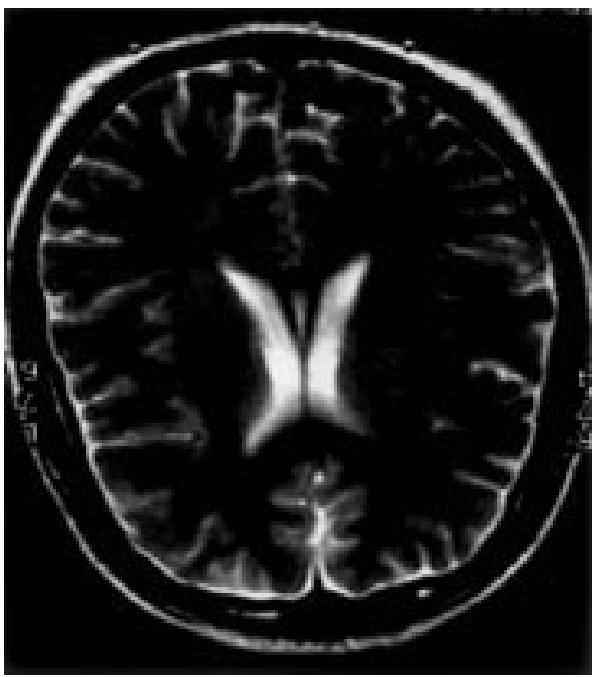

Figure 2 Magnetic resonance imaging of the brain in case 2. Normal appearing white matter. 
of the normal range for this enzyme. The low level of enzyme in the context of the family history and the personal history of the patient, however, suggest a carrier state for Krabbe's disease.

\section{DISCUSSION}

Early infantile Krabbe's disease causes rapid psychomotor decline with death within two years. ${ }^{4}$ Juvenile and adult forms have a more prolonged course and a milder phenotype..$^{5-9}$ Adult Krabbe's disease presenting primarily as "pure" spastic paraparesis is a rare phenotype..$^{10-13}$

The surprising finding in our cases was the lack of abnormal imaging findings despite the progression of the disease (over 22 years in the index case). MRI negative Krabbe's disease had not been reported before in adult cases, although it is recognised that MRI abnormalities may be difficult to identify early in the course of the disease. ${ }^{14}{ }^{15}$ The index case in our series had the disease for 22 years and despite abnormalities of evoked potentials had repeatedly normal MRI findings.

Objective evaluation of white matter signal intensity is difficult and appearances are sensitive to the acquisition sequence, the type of scanner used, and windowing of the images. In this case, comparable studies nine months apart in case 1 (fig $1 \mathrm{~A}$ and $1 \mathrm{~B}$ ) may show some progression in $\mathrm{T} 2$ weighted signal intensity in the posterior white matter.

The further unusual finding in our family was the presentation of the heterozygote (case 3). The father of the two siblings had GALC levels within the heterozygous range. He was initially investigated for falls. Clinical examination 20 years later-although showing normal power-revealed pathological enhancement of the lower limb reflexes. Although milder forms of spasticity have not been described before in adult Krabbe's disease, a heterozygote phenotype is apparent from psychological studies in one Krabbe's disease family, where there were significant differences in intelligence quotient between Krabbe's disease carriers and controls. ${ }^{16}$

As with other inherited diseases, advances in molecular biological techniques have enhanced our understanding of the heterogeneous nature of Krabbe's disease. ${ }^{17}$ GALC, a highly hydrophobic lysosomal enzyme, is composed of a heterodimeric complex of two subunits of $50 \mathrm{kDa}$ and $30 \mathrm{kDa}$, derived from an $80 \mathrm{kDa}$ precursor. ${ }^{18}$ Recent cloning of the GALC gene ${ }^{23}$ has allowed genotypic/phenotypic comparisons to be made in Krabbe's disease, and has shown that different mutations within this gene are associated with differing severity of disease, both in terms of age of onset and subsequent progression. One common mutation has been found in $40-50 \%$ of the mutant alleles in infantile cases of European or Mexican ancestry. ${ }^{19-21}$ Sixty five disease causing mutations and polymorphic changes within GALC have been described to date. ${ }^{22}$ The majority of mutations causing the adult form of Krabbe's disease have been shown to occur at the $5^{\prime}$ end of the gene, with infantile cases clustering at the $3^{\prime}$ end. ${ }^{123}$ Twelve of 14 mutations described in adult Krabbe's disease are located in the $50 \mathrm{kDa}$ subunit. ${ }^{10-12} 23-25$

Polymorphisms within the GALC gene have been shown to decrease the in vitro expression of GALC and may in part be responsible for pseudodeficiency states. ${ }^{23} 2426$ Similarly, expression studies of mutant alleles have suggested that phenotypic variation of cases of Krabbe's disease reflects varying degrees of reduction in GALC activity associated with the differing mutant alleles. ${ }^{3} 192023-252728$ Variation of phenotype between homozygotes within the same sibship, with presumably the same underlying GALC mutation, is harder to explain but has nevertheless been reported. ${ }^{8} 10232529$ Such variation is illustrated in the onset of disease between the homozygote siblings in this report (cases 1 and 2), onset being at age 11 in case 1 and at age 32 in case 2 . This variation within sibships may not be a function of the GALC mutation alone but may also be related to differing rates of psychosine turnover (discussed by Percy ${ }^{17}$ ).

This family illustrates the heterogeneity of adult onset Krabbe's disease, both in the phenotypic differences between homozygotes and heterozygotes and in the varying age of presentation in the homozygotes. The finding of normal imaging in adult onset Krabbe's disease simply extends this observation, but it does have the important implication that cases of idiopathic spastic paraparesis should be screened for Krabbe's disease.

\section{Authors' affiliations}

N P S Bajaj, N W Wood, K P Bhatia, Department of Clinical

Neurology, National Hospital for Neurology and Neurosurgery, Queen Square, London WC1, UK

A Waldman, Lysholm Department of Neuroradiology, National Hospital for Neurology and Neurosurgery

R Orrell, Department of Neurology, Royal Free Hospital, Pond Street, London NW3, UK

Correspondence to: Dr K P Bhatia, Institute of Neurology, Queen Square, London WC1N 3BG, UK; kbhatia@ion.ucl.ac.uk

Received 6 August 200

Accepted 8 November 2001

\section{REFERENCES}

1 Suzuki K, Suzuki Y. Globoid leucodystrophy (Krabbe's disease) deficiency of galactocerebrosidase $\beta$-galactosidase. Proc Natl Acad Sci USA 1970;66:302-9.

2 Chen YQ, Rafi MA, de Gala G, et al. Cloning and expression of cDNA encoding human galactocerebrosidase, the enzyme deficient in globoid cell leukodystrophy. Hum Mol Genet 1993;2:1841-5.

3 Sakai N, Inui K, Fuiii N, et al. Krabbe disease: isolation and characterisation of a full-length cDNA for human galactocerebrosidase. Biochem Biophys Res Commun 1994;198:485-91.

4 Suzuki K, Suzuki Y, Suzuki K. Galactosylceramide lipidosis: globoid leukodystrophy (Krabbe disease). In: Scriver CR, Beudet AL, Sly WS, Valle $D$, eds. The metabolic and molecular bases of inherited disease, 7th ed, vol 2. New York: McGraw-Hill, $1995: 2671-92$.

5 Thomas PK, Halpern JP, King RH, et al. Galactosylceramide lipidosis: novel presentation as a slowly progressive spinocerebellar degeneration. Ann Neurol 1984;16:618-20.

6 Loonen MC, Van Diggelen OP, Janse HC, et al. Late-onset globoid cell leukodystrophy (Krabbe's disease). Clinical and genetic delineation of two forms and their relation to the early-infantile form. Neuropediatrics 1985; 16:137-42

7 Goebel HH, Harzer K, Ernst JP, et al. Late-onset globoid cell leukodystrophy: unusual ultrastructural pathology and subtotal beta-galactocerebrosidase deficiency. J Child Neurol 1990;5:299-307.

8 Phelps M, Aicardi J, Vanier MT. Late onset Krabbe's leukodystrophy: a report of four cases. J Neurol Neurosurg Psychiatry 1991;54:293-6.

9 Kolodny EH, Raghavan S, Krivit W. Late-onset Krabbe disease (globoid cell leukodystrophy): clinical and biochemical features of 15 cases. Dev Neurosci 1991;13:232-9.

10 Turazzini M, Beltramello A, Bassi R, et al. Adult onset Krabbe's leukodystrophy: a report of 2 cases. Acta Neurol Scand 1997:96:413-15.

11 Satoh JI, Tokumoto H, Kurohara K, et al. Adult-onset Krabbe disease with homozygous T1853C mutation in the galactocerebrosidase gene. Unusual MRI findings of corticospinal tract demyelination. Neurology 1997;49:1392-9

12 Wenger DA, Rafi MA, Luzi P. Molecular genetics of Krabbe disease (globoid cell leukodystrophy): diagnostic and clinical implications. Hum Mutat 1997; 10:268-79.

13 Inatomi Y, Tomoda H, Itoh Y, et al. An adult patient with Krabbe's disease: the first case reported in Japan. Clin Neurol 1993;33:1 188 94.

14 Finelli DA, Tarr RW, Sawyer RN, et al. Deceptively normal MR in early infantile Krabbe disease. Am J Neuroradiol 1994;15:167-71.

15 Zafeiriou DI, Anastasiou AL, Michelakaki EM, et al. Early infantile Krabbe disease: deceptively normal magnetic resonance imaging and serial neurophysiological studies. Brain Dev 1997;19:488-91.

16 Christomanou H, Jaffe S, Martinius J, et al. Biochemical, genetic, psychometric, and neuropsychological studies in heterozygotes of a family with globoid cell leukodystrophy (Krabbe's disease). Hum Genet $1981 ; 58: 179-83$.

17 Percy AK. Krabbe continuum or clinical conundrum? Neurology 1997:49:1203-4.

18 Chen YQ, Wenger DA. Galactocerebrosidase from human urine: purification and partial characterisation. Biochim Biophys Acta 1993; 1170:53-61

19 Rafi MA, Luzi $P$, Chen $Y Q$, et al. A large deletion together with a point mutation in the GALC gene is a common mutant allele in patients with infantile Krabbe disease. Hum Mol Genet 1995;4:1285-9. 
20 Luzi $\mathbf{P}$, Rafi MA, Wenger DA. Characterisation of the large deletion in the GALC gene found in patients with Krabbe disease. Hum Mol Genet $1995 ; 4: 2335-8$

21 Kleijer WJ, Keulemans JL, van der Kraan M, et al. Prevalent mutations in the GALC gene of patients with Krabbe disease of Dutch and other European origin. J Inherit Metab Dis 1997;20:587-94.

22 Jardim LB, Giugliani R, Pires RF, et al. Protracted course of Krabbe disease in an adult patient bearing a novel mutation. Arch Neurol 1999;56:1014-17.

23 De Gasperi R, Gama Sosa MA, Sartorato EL, et al. Molecular heterogeneity of late-onset forms of globoid-cell leukodystrophy. Am J Hum Genet 1996:59:1233-42.

24 Luzi P, Rafi MA, Wenger DA. Multiple mutations in the GALC gene in a patient with adult-onset Krabbe disease. Ann Neurol 1996:40:116-19.
25 Bernardini GL, Herrera DG, Carson D, et al. Adult-onset Krabbe's disease in siblings with novel mutations in the galactocerebrosidase gene. Ann Neurol 1997;41:111-14

26 Wenger DA, Lovie E. Pseudodeficiencies of arylsulfatase A and galactocerebrosidase activities. Dev Neurosci 1991;13:216-21.

27 Tatsumi N, Inui K, Sakai N, et al. Molecular defects in Krabbe disease. Hum Mol Genet 1995:4:1865-8.

28 Rafi MA, Luzi P, Zlotogora J, et al. Two different mutations are responsible for Krabbe disease in the Druze and Moslem Arab populations in Israel. Hum Genet 1996;97:304-8.

29 Verdru P, Lammens M, Dom R, et al. Globoid cell leukodystrophy: a family with both late-infantile and adult type. Neurology $1991 ; 41: 1382-4$

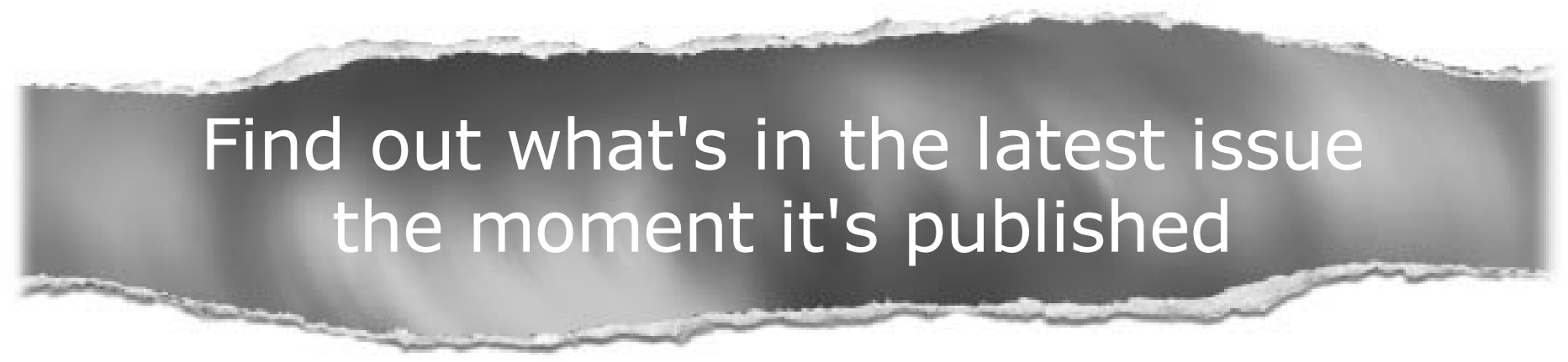

Email Alerts

Sign up to receive the table of contents by email every month. You can select from three alerts: Table of Contents (full), TOC Awareness (notice only); Journal of Neurology, Neurosurgery, and Psychiatry related announcements.

\section{www.jnnp.com}

